\title{
Research on the Construction of Online Open Course of Room Service and Management and the Application of Teaching Reform
}

\author{
ZhiHua Wang ${ }^{1, a}$ \\ ${ }^{1}$ Department of Tourism Management and Service Education, Chongqing University of Arts and \\ Sciences, Yongchuan, Chongqing, China \\ a email, 1061456382@qq.com
}

Keywords: Online and offline, Microlectures, Online open courses, Hybrid teaching method.

\begin{abstract}
The advent of the MOOCs era, it brings new opportunities and challenges to the teaching reform in universities. The "Room Service and Management" is the core course of hotel management in our university selected as the research object, expounding the foundation and goal of the course, designing and applicating of the online open course "Room Service and Management", it is hoped that it can be used for reference in the reform of similar courses.
\end{abstract}

\section{《客房服务与管理》在线开放课程建设与教学改革应用研究}

\author{
王志华1, a \\ 1重庆文理学院旅游管理与服务教育系, 永川, 重庆, 中国 \\ aemail, 1061456382@qq.com
}

关键词:线上线下; 微课; 在线开放课程; 混合式教学法

中文摘要. MOOCs时代的到来, 为高校教学改革带来了新的机遇和挑战。选取本校酒店管理 类专业核心课程《客房服务与管理》作为研究对象, 阐明了该课程建设的基础及目标, 对《客 房服务与管理》在线开放课程进行了设计及应用, 希望能对同类型课程的改革起到借鉴作用。

\section{1. 引言}

伴随信息化时代的到来, 大学生学习的特点发生了巨大的改变, 学生偏好使用移动设备 获取所需知识, 喜欢尝试新鲜事物及参与式学习, 注意力较容易分散。线上线下混合式教学 法可以充分满足当代大学生学习的特点, 利用线上微视频、网上论坛、线下项目教学、翻转 课堂、体验式教学等混合式教学法能够达到良好的教学效果。

\section{2. 《客房服务与管理》在线开放课程建设基础}

《客房服务与管理》作为本校的专业核心课程决定了在酒店管理类课程群中不可替代的 核心地位。该课程在本校开设的历史较长、积淀深厚, 已经先后在工商管理 (旅游管理方向) 专业及旅游管理服务与教育专业开设10余年，主要通过本校网络教学平台向全校师生开放。 该课程在本校五大教改政策导向下，作为核心课程改革项目已经进行了教学方法、教学内容 及考核方式的改革。该课程教师团队还将其作为典型课程在其他相关教改项目中进行了深入 研究, 效果显著。由于课程团队人员投入了大量的精力对该课程进行全面建设, 使得该课程 在各方面都有了较大的突破。根据每学期学院举行的教学评教系统显示, 学生评分都在90分 以上, 教学效果为优秀, 说明该课程教学效果显著, 教学质量稳定。 
该课程团队成员有着丰富的教学经验及行业实践经验, 曾多次参加相关高级别的学术研 讨会，主持与参与多项不同层次的相关教改项目，对该课程的改革具有较高的驾驭能力。该 课程团队是一支较为年轻的队伍, 具有较强的改革意识及创新精神, 因而该课程未来的改革 前景远大。

\section{3. 《客房服务与管理》在线开放课程建设目标}

学生可以利用碎片化时间进行《客房服务与管理》在线开放课程的灵活学习, 帮助提高 学生学习的满意度, 培养学生主动学习能力、自学能力及互助学习能力。该课程的建设要达 到以下目标:

\section{1 体例新颖, 强调适用}

打破传统学术结构体系，通过线上线下混合式教学方法，采用“项目导入，任务驱动”的 教学形式, 每个项目由完成目标、学习重难点、在线知识学习、任务导入、分组讨论、项目 汇报及交流、课后拓展等部分构成, 学生可以在完成工作任务的过程中学习相关知识, 将枯 燥的客房服务及管理的工作程序和规范条文转化为一个个真实的工作场景, 力求符合学生的 认知能力, 帮助学生更好的理解和掌握大纲知识, 达到预期一知识、能力及素养 “三位一体” 教学目标。

\section{2 活动丰富, 注重实践}

该课程采用线上线下混合式教学法方式，既有线上的影像观摩、讨论答疑、头脑风暴、 项目小组创想对话与交流等活动，又有线下的案例分析、小组汇报、情景模拟、角色扮演等 多样化的活动形式, 注重培养学生的业务操作能力与管理能力, 既增强了课程的趣味性与体 验性, 又方便了学生将理论知识内化为实践能力。

\section{3 考核创新, 突出过程与任务评价}

该课程考核评价应注重实践能力、应用能力和创新能力的考核, 既有学生在线作业考核、 阶段性测试、实践考核，又有学生线下的最终期末考核、实地实训考核，成绩评价由在线开 放后台+酒店客房主管+教师团队成员三方共同评定。

\section{4 形成系统化的教学资源}

该课程应配套教学大纲、教学题库、教学课件、教学参考书、客房行业标准等, 各教学 资源之间能够做到既相互补充又相互配合, 形成了一个完整的教学资源体, 能较好的保证教 师教学质量。

\section{4.《客房服务与管理》在线课程的设计及应用}

学习者登录相关学习平台，通过“课程名称”、“主题”“主讲教师”等相关内容快速检索该 课程相关信息, 还可以根据课程分类快速查找到该课程, 然后, 查找相关PPT、教学视频、 作业等相关板块。

\subsection{PPT课件及微视频制作}

根据大纲中的教学内容, PPT课件制作的内容共分为五个大项目, 每个项目中又包含二 到三个任务, 各具体内容主要包括学习目标、学习重难点、任务导入、分组讨论、课堂分享、 交流、探究、课后拓展等环节。

教学视频制作采用微课形式, 精选《客房服务与管理》课程的知识点及技能点提炼出各 个主题, 之后对各主题的具体内容进行重新梳理及编排，根据授课内容的具体情况制作出 
15-20分钟不等的8个微课, 各具体内容里面还可导入丰富的视频短片, 如高星级酒店房间设 施设备、高星级酒店客房部真实服务流程、客房部班前会等, 给学生营造真实的工作场景, 提高学生在线学习的体验感。微视频教学可作为线下课堂预习材料及复习拓展巩固资料。具 体建设内容如下:

表1 《客房服务与管理》课程微视频教学内容

\begin{tabular}{|c|c|c|c|c|}
\hline \multirow{2}{*}{ 课程名称 } & \multicolumn{4}{|c|}{ 客房服务与管理 } \\
\hline & 8 个 & 预计总时长 & \multicolumn{2}{|c|}{145 分 } \\
\hline \multirow{9}{*}{$\begin{array}{l}\text { 视 } \\
\text { 频 } \\
\text { 情 } \\
\text { 况 }\end{array}$} & 序号 & 知识 & & 时长 \\
\hline & 1 & 客房部 & & 20 \\
\hline & 2 & 客房部主 & －作任务 & 15 \\
\hline & 3 & 客房部) & & 15 \\
\hline & 4 & 客房房间类 & 客房设备 & 20 \\
\hline & 5 & 客房部 & & 15 \\
\hline & 6 & 客房楼 & & 20 \\
\hline & 7 & 客房中 & & 20 \\
\hline & 8 & 客房部 & & 20 \\
\hline
\end{tabular}

\section{2 课堂活动安排}

线上线下教学活动由课前、课中及课后三个环节组成。课前环节, 学生进行线上微课学 习及线上各版块的互动，如在线答疑讨论、在线头脑风暴、在线项目小组创想对话与交流， 教师则通过参与线上活动发现学生共性问题, 为线下备课提供素材。课中环节, 学生进入线 下参与课堂活动, 如任务完成、分组讨论、情景模拟、角色扮演、案例分析等, 教师在线下 课堂主要扮演活动的组织者及引导者, 学生则充分发挥主动性, 积极投入课堂活动。课后, 学生与教师可以再此回到线上, 如果学生有问题可以进入在线平台中的在线答疑、问题留言 等板块进行互动和交流, 互动对象为教师与学生、学生与学生间进行深入讨论。通过线上线 下融合学习, 实现课前、课中及课后三个环节的无缝对接, 能够使学生获得深度的学习体验, 顺利达成教学目标。

\section{3 作业、解析及阶段性自测}

教师团队人员及校企合作高星级酒店客房部主管共同建立作业题库、解析及阶段性自测 试卷, 内容包括: 客观题、情景判断题、论述题、思考题、案例分析、实操题等应用类题型, 团队人员可以在后台进行自动或手动生成试卷及阅卷。学习者学完规定的课时, 系统将自动 跳出作业及阶段性自测试卷, 学习者可在线完成作业及阶段性自测试卷, 完成提交后进入后 台作业评审, 将给出评阅结果, 错误部分也将给出具体的解析内容, 还可以在答疑讨论板块 给团队成员留言，团队人员将对学生作业及阶段性自测试卷进行辅导及讨论互动。

\section{4 课程成绩评定}

课程总评成绩 $(100 \%)=$ 平时成绩（40\%）+实践考核（30\%）+期末考核成绩（30\%） 其中实践考核 $(100$ 分 $)=$ 业务操作考核成绩（线下50分）+项目汇报（线下50分） 
平时成绩 (100分）=学生的出勤情况（20分）（线上自动打卡+线下课堂出勤情况）+线 上线下课堂讨论、课堂表现（40分）+线上作业及阶段性自测情况（线上40分）

\section{5 相关参考资料的配置}

相关参考资料作为学生课前知识了解、课后知识拓展的重要资源, 不仅给普通学生提供 了自主学习的材料, 还给学有余力的学生提供了进一步探究学习的机会, 实现了课后学习的 延伸和拓展。该课程主要通过上传客房部行业质量标准、配置在线课程资源二维码扫描、制 作高星级酒店客房部网页链接等方式辅助学生自主学习视频资料、影像资料、文档资料及获 取酒店行业客房部发展最新动态。

\section{6 课程维护及管理}

该课程在线开放课程的初期建设固然重要，但课程的同步维护及管理也不容忽视，才能 确保该课程的长足发展。该课程每学期需要定期进行教学方法、教学手段、考核方式、教学 效果的研讨及总结, 不断改进该课程的教学模式, 提升该课程的教学质量和教学效果。教师 团队还应时刻关注酒店行业客房部发展走向, 积极导入酒店客房部最新研究成果及发展的最 新动态，不断完善该课程立体化教学资源，制作符合新时代背景下酒店管理类专业学生特点 的集客房基础理论性、实用性与趣味性为一体的教学资源, 逐步建成具有明显特色的高质量 的《客房服务与管理》在线开放课程。

\section{5. 结束语}

通过线上线下混合式教学法的改革，《客房服务与管理》在线开放课程将在本校起到较 好的示范带头作用, 并逐步建设成为省级精品课程, 此外, 《客房服务与管理》在线开放课 程也将成为职业培训、高星级酒店客房部培训学习的“金果”教学资源，通过不断完善该课程 相关教学资源, 逐步提高该课程服务社会的能力, 希望能够在西部应用型高校及行业培训中 获得良好的教学效果。

\section{致谢}

本文为重庆市高等教育教学改革研究一般项目《高校双创复合型旅游管理人才培养及理 实一体化平台运营研究与实践》(183031)、重庆文理学院 2017 年度新工科研究与实践重点项 目《大旅游背景下旅游管理复合型人才多元化培养创新研究》（170103）及 2019 年精品在线 开放课程培育项目《客房服务与管理》课程的阶段性成果之一。

\section{References}

[1] Su Jun Lai, Research on the current situation and effective path of online open courses in independent colleges in Pearl river delta region, Policy Research \& Exploration, vol. 03, pp. 77-78, 2019.

[2] Jia Yuan Lu,Xing Wu, Design and implementation of MOOC course platform, The Chinese Journal of ICT in Education, vol. 05, pp.69-72, 2015.

[3] Jing Lei Zhang, Analysis on the key factors of the teaching model of "Flipping classroom", Distance Education in China, vol.10, pp.59-64, 2013.

[4] Wei Bing Liang, Discussion on mixed teaching mode based on constructivism, China Training, vol.04, pp. 77-78, 2018.

[5] Qian Qian Shi, Optimizing the design of college English online open course, Western China Quality Education, vol.07, pp. 123-124, 2019. 